\title{
Um projeto \\ para mudar o Brasil
}

\author{
LÚCIO ALCÂNTARA
}

$\mathrm{E}$ M JANEIRO de 2006, parlamentares das bancadas federais do Ceará, Rio Grande do Norte, Paraíba e Pernambuco fizeram uma moção de apoio ao governo federal, pelo empenho na realização do projeto de transposição das águas do Rio São Francisco.

Um documento produzido na ocasião observa: "somente alguém que sentiu na pele a situação de enfrentar longos períodos de estiagem, vendo-se obrigado a deixar a sua terra natal em busca de uma vida melhor, poderia entender o clamor do nosso povo e não se deixar levar pelas pressões dos que são contrários a oferecer um pouco d'água a quem tem sede".

Independentemente de pressões localizadas e interpretações emocionais, tão prosaicas na história brasileira, mas pouco indicadas a este ou a outros casos, a transposição das águas do Rio São Francisco vem deixando de ser uma miragem no deserto para transformar-se numa realidade concreta.

Ceará, Pernambuco, Paraíba e Rio Grande do Norte seriam os estados diretamente beneficiados, mas um conjunto de medidas em prol do Velho Chico estenderia os efeitos das melhorias para os estados vizinhos.

Antigas, as negociações foram sempre marcadas por avanços e recuos, e hoje são coordenadas pelo Ministério da Integração Nacional, com o acompanhamento de vários ministérios e do Comitê da Bacia Hidrográfica do Rio São Francisco, no qual a sociedade civil tem importante participação.

Devemos esclarecer que não se trata de uma questão nordestina, mas de um grande tema pátrio. A distribuição da água no território nacional é assunto que diz respeito a cada um de nós, brasileiros. E o princípio da federação, que nos rege, pressupõe compromisso com o todo, e solidariedade entre os estadosmembros.

\section{Toada antiga}

Essa é uma toada antiga. Nos tempos do Império, o deputado cearense Marcos Macedo já falava sobre a importância das águas do São Francisco no atendimento a outros estados.

Mais de 500 municípios de sete estados brasileiros são atingidos pela bacia do Rio São Francisco, que nasce na Serra da Canastra, em Minas Gerais, e desemboca no mar, entre Sergipe e Alagoas, perfazendo um longo e sinuoso percurso de 2.800 quilômetros de extensão. 


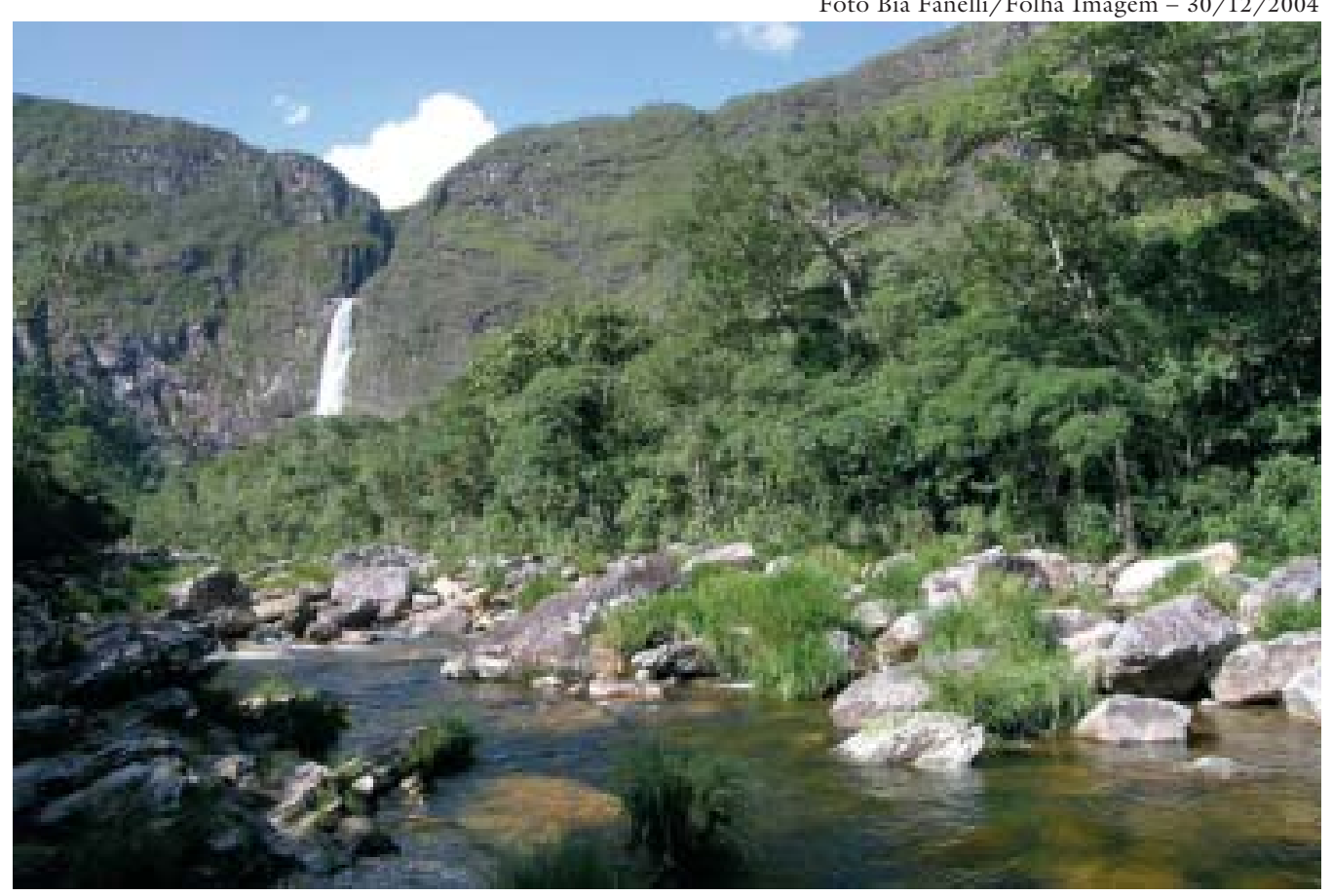

A famosa cachoeira Casca Danta na Serra da Canastra (MG).

Por envolver tamanha quantidade de lugares, climas, pessoas e interesses, num raio de abrangência que abarca as regiões Sudeste, Centro-Oeste e Nordeste, a transposição das águas do Velho Chico incita o debate político, mobiliza forças sociais, mexe com prerrogativas técnicas e divide a opinião pública.

Junte-se a isso a má vontade nascida da desinformação de alguns setores do pensamento nacional, para os quais pouco vale dizer que somente uma pequena quantidade da água do rio seria desviada para abastecimento da população, justamente a que é jogada no mar sem proveito algum.

As vozes que se levantam contra o projeto alegam que ele causaria males ecológicos e econômicos ao país, ainda que estejam em andamento ações de controle da erosão na bacia do rio; monitoramento da qualidade da água; reflorestamento das nascentes, margens e áreas degradas na bacia do São Francisco e estudos de conformação do leito navegável.

O pior cego é o que não quer ver. Hoje, sabemos que é possível erguer obras estruturantes fundamentais, de forma planejada, responsável e conseqüente, evitando desperdícios de verba pública, estorvos para a população e danos ao meio ambiente.

É bom esclarecer também que a transposição do Rio São Francisco será bem-vinda por impulsionar um projeto maior de interligação de bacias, capaz de levar o Nordeste a um novo patamar de desenvolvimento. Com a água transposta, alguns açudes estratégicos poderão multiplicar a sua vazão regularizada, e apenas nos anos críticos de estiagem a transposição ocorreria nos limites máximos. Para diminuir as perdas por evaporação, já estamos reforçando a gestão racional dos reservatórios públicos. 
Por sua vez, a irrigação no Vale do São Francisco, que pode expandir-se por mais 800 mil hectares nos próximos anos, significa maior produtividade agrícola, incentivo à fruticultura, criação de novos empregos e geração de renda para milhares de famílias, especialmente na região do semi-árido, a mais penalizada pelas estiagens e pelo descaso político.

Apesar das polêmicas e delongas, nunca estivemos tão próximos de traduzir dados em obras. É importante, portanto, que todas as dúvidas sejam esclarecidas, para que nenhum Estado se julgue prejudicado pela realização desse empreendimento, que por sua vez, não prejudicará o Rio São Francisco, esse formidável patrimônio nacional, cujo leito continuará passando por onde sempre passou.

O objetivo, é bom esclarecer, não é acabar com a seca, mas amenizar os seus efeitos, contribuindo para o convívio harmônico do homem com o semiárido. Não creio que falte solidariedade ao povo baiano, mineiro, paulista ou carioca para compreender a magnitude de uma aspiração de tantos anos.

\section{A fisionomia de um projeto}

O "rio da integração nacional”, como é chamado o São Francisco, foi descoberto, praticamente junto com o Brasil, em 1502. Apesar dos maus tratos a que foi submetido ao longo da história, continua assemelhando-se a uma mão aberta e generosa, recebendo água de 168 afluentes e banhando os estados de Minas Gerais, Bahia, Pernambuco, Sergipe e Alagoas; e sua bacia hidrográfica também envolve parte de Goiás e Distrito Federal.

Mesmo durante a estação seca, é a represa de Sobradinho que garante a regularidade de vazão do São Francisco, alimentando cinco grandes companhias hidrelétricas, como a do São Francisco (Chesf). As águas do rio põem em funcionamento o sistema nervoso das hidrelétricas, alimentando-lhes os geradores e, depois disso, seguem para o mar.

O projeto de transposição prevê a captação de 26 metros cúbicos por segundo $\left(\mathrm{m}^{3} / \mathrm{s}\right)$, ou seja, $1,4 \%$ do volume de água que o rio despeja no mar. Essa água será preciosa para o abastecimento das bacias dos rios Jaguaribe, no Ceará; Apodi, no Rio Grande do Norte; Piranhas-Açu, na Paraíba e no Rio Grande do Norte; Paraíba, na Paraíba; e Moxotó e Brígida, em Pernambuco.

Dados do Ministério da Integração Nacional esclarecem que, hoje, 95\% do volume médio liberado pela barragem de Sobradinho - $1.850 \mathrm{~m}^{3} / \mathrm{s}$ - são despejados na foz e apenas $5 \%$ são consumidos no Vale. Nos anos chuvosos, a vazão de Sobradinho chega a ultrapassar 15 mil metros cúbicos por segundo, e todo esse excedente também vai para o mar, revelam estudos técnicos.

Não se quer, de maneira alguma, tomar medidas que agravem as condições de degradação do ecossistema, pois o rio já tem problemas em relação às suas nascentes e ao longo de suas margens. Ao contrário, o que almejamos é uma recuperação que pode significar nova vida para o São Francisco. 
O Programa de Revitalização, cujas ações já se iniciaram, contempla justamente a melhoria da navegação no rio, o que trará avanços para o transporte de soja, algodão, milho e outros grãos, que transitam do oeste da Bahia para o porto de Juazeiro, também na Bahia, escoando-se a produção, por ferrovia, para os maiores portos do Nordeste.

Serão financiados projetos de reflorestamento das margens do rio, recuperação do leito, combate à erosão e ao assoreamento, além de obras de saneamento, tratamento de esgotos e projetos de desenvolvimento sustentável para atender as populações ribeirinhas.

Doze milhões de pessoas podem ter o abastecimento garantido com a captação de água do Velho Chico, dividindo-se o projeto em dois eixos: o canal leste, que atenderá a Pernambuco e Paraíba, e o canal norte, responsável pelo abastecimento do Ceará, Paraíba, Rio Grande do Norte e Pernambuco.

\section{A seca e as jóias da coroa}

Tratada geralmente com excessos sentimentais, parcialidade política e pouca fundamentação científica, a questão das secas periódicas continua a desafiar o Nordeste. Relatos históricos garantem que D. Pedro II jurou vender até a última jóia da coroa para que nenhum cearense morresse de fome. Com isso, provou apenas que os flagelos não se resolvem com belas frases.

Durante muitos anos, a açudagem foi considerada a nossa única saída para os humores do clima. Com o tempo, porém, a construção de barragens e grandes reservatórios, por si só, mostrou-se incapaz de promover melhorias na agricultura e assegurar prosperidade para as regiões secas.

Hoje, afinal, sabemos que não basta acumular água. É preciso investir numa política conseqüente de gestão dos recursos hídricos, capaz de planificar medidas estruturantes, interligando bacias e conectando os esforços da União, estados e municípios. Há inúmeros projetos de transferência de água muito bem-sucedidos na Rússia, nos Estados Unidos e em vários outros países.

Nesse ponto, apesar das gigantescas dificuldades, o Ceará tem muito o que dizer. Já avançamos bastante no sistema de integração das águas, desenvolvido de forma planejada há quinze anos, com a construção de açudes, canais, estações de tratamento, adutoras e poços profundos que se comunicam por todo o Estado.

Esse sistema leva a água das regiões úmidas para as zonas secas. Por causa disso, o Ceará possui hoje 2.600 quilômetros de rios perenizados.

Nesse ponto, é bom que se diga que a Política Estadual dos Recursos Hídricos adota os princípios básicos de descentralização, integração e participação comunitária, para garantir que a água seja usada de forma racional pela sociedade, representada nos Comitês de Bacias Hidrográficas.

No longo caminho rumo ao desenvolvimento sustentável, uma das mais importantes obras hídricas do país é a transposição das águas do Velho Chico, e o Ceará está se preparando para a concretização desse projeto, com sua política 
de recursos hídricos e pontos de apoio, dentre os quais se destaca um grande canal que vai interligar vários municípios do interior.

\section{O canal da integração}

Um canal gigantesco, o maior já construído em concreto no país, com 225 quilômetros de extensão, é a obra mais fundamental para o processo de fortalecimento das condições de convivência com o semi-árido cearense. Estamos falando do Canal da Integração, que já teve o seu primeiro trecho inaugurado pelo governo do Estado.

De saída, o Canal vai transportar as águas do açude Castanhão, no município de Nova Jaguaribara, a pontos distintos do interior cearense. Com isso, a agricultura irrigada ganhará um grande impulso, pois a obra vai fortalecer a produção de frutas na região do Baixo Jaguaribe. O abastecimento humano de Fortaleza e comunidades ao longo do Canal também estará garantido nas próximas três décadas, mesmo em períodos de estiagem.

Ao final do seu percurso, o Canal da Integração terá passado por doze municípios, irrigando pelo menos 33 mil hectares e garantindo água para o Complexo Industrial do Pecém e os distritos industriais de Maracanaú, Horizonte e Pacajus.

O mais importante será quando a segunda e terceira etapas da obra estiverem concluídas, o Ceará será o primeiro Estado em condições de receber as águas provenientes da transposição do Rio São Francisco.

\section{Bons tempos para o semi-árido}

O projeto do São Francisco está estritamente ligado ao convívio harmonioso com o semi-árido, uma região densamente povoada e com demandas históricas a serem sanadas.

Por isso, o governo federal estruturou o Programa de Desenvolvimento Sustentável do Semi-Árido e da Bacia Hidrográfica do Rio São Francisco, planificando medidas que se dividem entre os seguintes programas: Revitalização do Rio São Francisco, Combate à Desertificação e Mitigação dos Efeitos da Seca, Suprimento de Água para Populações Rurais e Urbanas, Programa Conviver para a Região Semi-Árida e Programa de Integração de Bacias Hidrográficas.

Todos esses programas se dividem em uma série de ações que visam proteger o rio e beneficiar a população do entorno. $\mathrm{O}$ sertão nordestino, enfim sabemos, precisa de apoio político, investimentos bem direcionados e obras estruturantes para mostrar a sua pujança e inaugurar uma nova era econômica.

Nos últimos anos, muitas atividades estão sendo estimuladas no semi-árido nordestino, além da agricultura familiar. Pesquisas e experiências desenvolvidas nas últimas décadas comprovam que a aparente hostilidade da região é propícia a atividades lucrativas, como fruticultura, aqüicultura, ovinocaprinocultura, apicultura, produção de oleaginosas (mamona, amendoim, gergelim, girassol), além do beneficiamento de riquezas minerais, do turismo ecológico, esportivo e religioso e da exploração do artesanato. 
Os estados precisam estar atentos para não desperdiçar oportunidades de investimentos nem adiar o processo de crescimento, que se faz de forma integrada, em diversas frentes, dentre as quais se destaca a educação para o convívio com o semi-árido.

Em janeiro de 2006, o governo do Ceará lançou a Unidade de Formação do Capital Humano do Campo (Unicampo), que vai articular uma grande rede para a troca de experiências, conhecimentos e técnicas agrícolas entre pequenos agricultores, empresários rurais e instituições de ensino. Uma troca que vai beneficiar 30.000 pessoas somente em 2006, por meio da promoção de teleconferências, seminários, oficinas, cursos, reuniões e eventos de capacitação.

A idéia é o combate intenso ao analfabetismo, o repasse de técnicas agrícolas e a conscientização para a preservação do meio ambiente, dentre outros pontos importantes. Instituições públicas, entidades privadas, movimentos sociais, conselhos setoriais e municipais, instituições financeiras, organizações de classe e instituições de ensino e pesquisa fazem parte desse grande mutirão para a qualificação da mão-de-obra.

A Unicampo integra o eixo de Desenvolvimento Humano do Programa Sertão Vivo, que envolve quinze secretarias de Estado e fundamenta as suas ações na geração de trabalho e renda, infra-estrutura básica e hídrica, meioambiente e tecnologia, além de desenvolvimento humano.

\section{Ampliar o debate}

Estamos ampliando o debate político e fomentando a criação de redes de parlamentares nos vários estados brasileiros e municípios do semi-árido, a fim de acompanhar e implementar o Programa de Ação Nacional de Combate à Desertificação e Mitigação dos Efeitos da Seca (PAN), que conta com o envolvimento dos vários ministérios, instâncias governamentais e da sociedade civil.

Ceará, Pernambuco, Piauí, Bahia, Maranhão, Alagoas, Paraíba, Rio Grande do Norte, Sergipe, Espírito Santo e Minas Gerais estão juntos nessa luta. O PAN, junto com medidas sérias de integração hídrica, pode levar o semi-árido brasileiro a um novo modelo de desenvolvimento, com base na redução da pobreza e das desigualdades sociais, na ampliação da capacidade produtiva e na proteção ambiental. Obras como o Canal da Integração e a transposição das águas do Rio São Francisco são fundamentais para transformarmos intenções em realidade.

Hoje, os programas que dão certo evitam pulverização de recursos, promovem a articulação das ações setoriais do governo e mobilizam forças da sociedade civil, principalmente dos beneficiários das medidas, formando parcerias estratégicas e duradouras. A articulação institucional intergovernamental potencializa esforços e recursos, tornando possível a complementaridade de ações.

Só para se ter uma idéia, hoje, o Ministério das Cidades executa um projeto de saneamento básico que envolve 84 municípios da bacia do São Francisco, no valor de R\$ 660 milhões, pois 250 comunidades despejam esgotos in natura na calha do rio. 
Por fim, se a transposição do Rio São Francisco, por um lado, não resolve os problemas referentes à falta de água no Nordeste, por outro, contribui imensamente para a garantia de condições mais dignas para milhares de famílias. Contudo, o debate só chegará a bom termo se as prerrogativas nacionais forem colocadas acima das conveniências políticas e muito além dos interesses de cada região.

Lúcio Alcântara é governador do Estado do Ceará (2003-2007). É médico, membro da Academia Cearense de Letras, foi senador da República (1995-2002), vice-governador do Estado do Ceará (1991-1994), deputado federal (1983-1991) e prefeito de Fortaleza (1979-1982). @-lucioalc@gabgov.ce.gov.br

Recebido em 17.2.2006 e aceito em 20.2.2006. 